\title{
Conservation, Preservation, and Digitization
}

\section{Clifford A. Lynch and Edwin B. Brownrigg}

Considerable attention has been focused recently on the problems of conservation and preservation of library materials. Particularly daunting are the scale of the problems and the enormous ongoing investment that will be required to address them. Currently proposed approaches include extensive microfilming of material, deacidification, and other repair measures. It is proposed that digital technologies be used to accomplish simultaneously the aims of conservation and improved access to materials. Various technologies are reviewed. Such an approach to conservation would form a natural extension to the current growth of electronic publishing, online catalogs, and online databases of journal abstracts. Furthermore, it would provide the greatest return for the massive investment that will be needed to save our deteriorating collections.

onservation and preservation present serious problems for the library community today. However, these problems are generally considered in isolation, without much reference to major trends in the development of library service or to the impact of library automation, widespread access to computers, and telecommunnications on both the nature and delivery of library service. In fact, conservation and preservation issues are often the province of people in the library who have been least affected by developments in technology and library automation: archivists, collection management specialists, etc. These people have always dealt with books as artifacts, and historically their concern has been the preservation and management of the printed word. This orientation is clearly reflected in classic works on conservation and preservation, such as the book by Cunha and Cunha entitled Conservation of Library Materials. ${ }^{1}$

Thus, the approach to conservation and preservation has been to try to save what exists-where possible, to save the physi- cal artifacts themselves, and where this is not possible, to create and save surrogates for the physical artifacts in the tangible form of microfiche. Up to a point these efforts obviously have been worthwhile: a beautifully produced book is a thing worth saving in its own right, and books as artifacts have considerable historical interest.

However, the nature of library services is changing. In times past, the library has been a repository for artifacts of the printed word. Today, it is taking on a more dynamic role as both a repository and a distributor of information (as distinct from artifacts). ${ }^{2}$ This transformation raises some difficult questions about the wisdom of current approaches to conservation and preservation.

\section{THE ACCESS REVOLUTION}

The advent of the online catalog has made it possible to provide remote access to the bibliographic holdings of libraries from computer terminals. This permits the identification of materials of interest

Clifford A. Lynch and Edwin B. Brownrigg are at the Division of Library Automation, University of California, Office of the President and Universitywide Services, Berkeley, California 94720. The authors would like to thank Mary Jean Moore for editorial assistance. This paper was presented at the ACRL Fourth National Conference in Baltimore, April 9-12, 1986. 다fford A. Lynch and Edwin B. Brownrigg, 1986. 
from a patron's home or office and provides a superior means of searching the library's holdings.

In spite of their advantages, however, online catalogs still have limitations. In general, they contain only monographs, providing little access to journal literature, which is critical, for example, in scientific research. Automated access to the latter is offered today by systems such as DIALOG and BRS, although the user interfaces for these systems are so complicated that use is largely limited to trained searchers or inveterate computer users. Fortunately these two sources of information should converge over the next few years, providing the end user with the ability to readily identify journal literature of interest.

From the user's point of view, an even more serious limitation is that online catalogs can only provide references to information, not the information itself. Thus, online catalogs simply form the backbone for far more extensive electronic publishing and document delivery systems to come. They deal with identification of material; the next challenge is to deliver the material electronically to the end user. Meeting this challenge requires complex technologies in the areas of telecommunications, computing, and electronic imaging. ${ }^{3,4}$ For any activity that affects a library's collections, such as conversion to microfilm to save space, acquisition of new materials, preservation and conservation, or migration of little-used material to dense storage, the library must look ahead to the new world of information delivery and begin the lengthy and costly conversion of collections to a form amenable to such delivery.

\section{CURRENT APPROACHES TO CONSERVATION AND PRESERVATION}

The current strategies for conservation and preservation of library materials include restoration, bulk deacidification, repair, and microfilming. ${ }^{5}$

For rare and valuable works of great significance, elaborate restoration and repair techniques have been developed. These techniques have been used to wonderful effect on illuminated manuscripts, early books, and the like. Only a relatively small number of threatened works justify such treatment, as is consistent with the handling of works of art in museums.

For books that are rotting because of the use of acid paper, various mass deacidification schemes have been proposed. Experience with these techniques is limited, however. If they work and if they prove to be cost-effective, they will preserve the status quo for the books that are treated.

Many books are in disrepair due to hard use or deterioration of their bindings. In some such cases, rebinding the work gives it a new lease on life, and, when this is cost-effective, it also preserves the status quo.

Books that are extremely fragile are being microfilmed page by page. These microfilms are then copied, and the master copies are stored in central, environmentally controlled repositories while copies replace the damaged book on the shelf. Although the contents of such books are preserved, access is greatly reduced. In general, it is impractical to circulate microfilm, and microfilm is almost universally loathed by library patrons, who have demonstrated that they will go to almost any lengths to avoid using it. Finally, microfilm is expensive to copy, which inhibits resource sharing, and it does not hold up well under heavy use.

In no case is the end product of these strategies converted to a form more hospitable to delivery over telecommunications media. Leaving aside rare works (the works of art), deacidification and rebinding leave the patron neither better nor worse off. However, microfilming greatly reduces access to the microfilmed material, and the patron is far worse off.

\section{DIGITIZATION FOR CONSERVATION AND PRESERVATION}

Capture of a work in digital images is an attractive alternative to microfilming. Since in both cases a book has to be scanned page by page, the predominant cost will be labor. Any extra expense of 
digitizing is marginal and is far outweighed by the value of the end product. Moreover, digital scanners and image storage devices are dropping rapidly in price.

Depending on how the economics and effectiveness of rebinding and deacidification turn out, digitization may prove to be an alternative to these strategies as well. In the next section, in fact, we argue that even if digitization costs more than deacidification it is still worth considering since it represents an investment in the future and prospectively protects the work. In the case of works of art, where the cost of preservation is a secondary issue, digitization may provide an attractive supplementary activity since access to the work can then be provided through the digital copy without any further threat to the original artifact. Thus, digitization could provide wide access to rare books that today are protected from use by any but the most serious and trustworthy scholars.

Consider the following attributes of digital images:

- They do not deteriorate with use. In fact, each use of a stored digital image causes the data to be read, validated, and corrected via error-correcting codes, thus permitting early detection and automatic correction of any deterioration in the storage media.

- They can be copied quickly and at virtually no cost. Any kind of digital information can be duplicated endlessly with no loss in quality, without human intervention, and at high speed and low cost. Although legal questions in regards to copyright must also be considered, ${ }^{6}$ they are often irrelevant for older works that are being preserved since the copyright has expired.

- Copies can be transmitted over a network at high speed and low cost. This attribute makes archives of digitized works possible; they can be duplicated and sent across the country to the requester via automated systems in a matter of minutes, or perhaps a few hours if the system is busy. Consequently, resource sharing becomes more practical, and it is not necessary for each library to retain copies of the microfilm for each work or to call for copies of these to be shipped (perhaps weeks later) from a central clearinghouse.

- Digital data are much less vulnerable to disaster and environmental threats. Digital information, especially on optical disks, does not deteriorate rapidly. When deterioriation occurs, the information can be copied easily. Since digital information is easy to copy, it is feasible to store copies at several geographically diverse repositories, removing the threat that a natural disaster will destroy the only available copy.

Thus, digital images solve not only the immediate conservation and preservation problem but also the problem in the longterm. In addition, they are easier to use, deliver, and share.

\section{ECONOMIC AND POLICY QUESTIONS}

Given then, that digitization is a desirable objective, the following economic and policy questions have to be addressed.

- What books are valuable as artifacts and thus require the kind of treatment accorded works of art?

We would argue that the answer to this question is to preserve liberally. Books as artifacts have considerable value, and wholesale elimination of examples of publishing from certain presses, countries, or historical periods would be a tragic loss.

- How should material from a collection be selected for digitization?

We might decide to digitize a book for one of three reasons: (1) Because it is disintegrating and needs to be copied. In this case we must act to preserve the work, and, if the cost of digitization is competitive with other techniques (such as microfilming), it should be used. In cases in which digitization is more costly than other approaches, such as deacidification or rebinding, we must decide if the extra benefits of digitization justify the extra costs; (2) because it is rare or delicate and, although not in immediate danger, we want to 
protect the book prospectively and permit its contents to be widely used; and (3) because it is often requested and we want it in a form appropriate for digital delivery via a network. Note that this has nothing to do with conservation and preservation. In fact, the parts of a collection that are most endangered today probably receive relatively light use overall.

Balancing the importance of these three criteria for digitization, particularly in the face of widespread deterioration of the collection and insufficient funding, is difficult. To a certain extent, this amounts to finding a balance between funding priorities for preservation and access.

In addition to these policy questions, there are a variety of more technical and operational issues that must be addressed. One such issue is the development of appropriate standards for the storage and transfer of images. Some of the standards under development for Group IV digital facsimile devices will be applicable here, as will some of the standards being developed for optical disk storage (particularly since optical disks are the natural storage medium for digital images). Other issues that must be addressed include the creation of links between bibliographic records and digital images of a book, research in appropriate technology for displays and user inter- faces to integrate the online catalog with document delivery, and the development of a repository system for digitized material to encourage resource sharing and eliminate duplication of effort on a national basis. In addition, effective use of digital images will require the installation of low-cost, broad-band telecommunications networks. Packet switching and satellite technology are ideal for these purposes.

\section{CONCLUSIONS}

Conservation and preservation will demand substantial sums of money during the remainder of the century if library collections in America are to be saved. At the same time, the library in the year 2000 will be radically different than the library of 1960. This transformation, which is well under way, has been costly since it has required the introduction of a massive amount of computer and telecommunications technology into the library-and the change is far from complete.

Saving the collections and revolutionizing access to them can be treated as independent problems competing for funds. In our view, this would be a major error since these two apparently disparate problems are in fact closely related. Conservation and preservation can become an investment in an increasingly obsolete status quo or it can become an investment toward the future.

\section{REFERENCES}

1. George M. Cunha and Dorothy G. Cunha, Conservation of Library Materials: A Manual and Bibliography of the Care, Repair and Restoration of Library Materials, 2v. (Metuchen, N.J.: Scarecrow, 1971).

2. Edwin B. Brownrigg and Clifford A. Lynch, "Online Catalogs: Through a Glass Darkly," Information Technology and Libraries 2:104-15 (Mar. 1983).

3. Clifford A. Lynch and Edwin B. Brownrigg, "Library Applications of Electronic Imaging Technology" Information Technology and Libraries (in press).

4. Clifford A. Lynch and Edwin B. Brownrigg, "Document Delivery and Packet Facsimile," Proceedings of the 48th ASIS Annual Meeting 22:11-14 (1985).

5. University of California, Office of the Executive Director of Universitywide Library Planning, Conservation of the Collections: A Supplement to the University of California Libraries: A Plan for Development, 1978-88, (Berkeley, Calif.: Univ. of California Pr., 1983).

6. Edwin B. Brownrigg and Clifford A. Lynch, "Electrons, Electronic Publishing, and Electronic Display," Information Technology and Libraries 4:201-7 (Sept. 1985). 


\section{Your invitation to enter the 1987

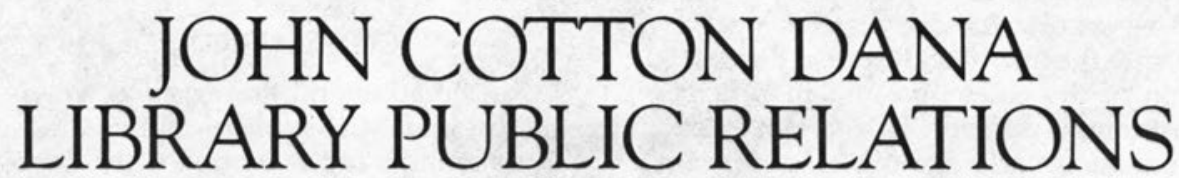 AWARDS CONTEST}

TF YOU'VE DONE an outstanding job of making your community more aware of your library, the John Cotton Dana Library Public Relations Awards Contest can tell the world about your efforts.

Your entry will be considered among those from libraries of all types, sizes, and budgets. Entries are judged by a panel of your peers, and two types of awards are given.

\section{The John Cotton Dana Award}

This award is given for a library's total annual, coordinated public relations program, including publicity, programs, advertising, publications, exhibits, special events, promotions, and audiovisual presentations.

\section{The Special Award}

The Special Award is given in recognition of a part of your public relations program - a fund-raising campaign, a series of adult or children's programs, or any other special project.

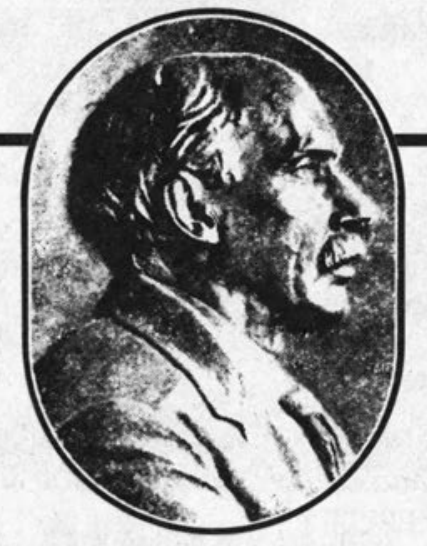

\section{Contest Dates}

Entries for the 1987 John Cotton Dana Library Public Relations Awards Contest may reflect any one of the following time frames:

- Calendar year 1986 (January-December)

- School Year 1985/6 (Fall-Spring)

- Special project which ends in 1986.

The deadline for entries is February 2, 1987.
Awards Ceremony

Official award citations will be presented to contest winners at the 1987 annual conference of the American Library Association, at a reception hosted by The H.W. Wilson Company.

\section{Sponsorship}

The John Cotton Dana Library Public Relations Awards Contest is sponsored jointly by The H.W. Wilson Company and the Public Relations Section of the Library Administration and Management Association, a division of the American Library Association.

\section{To Enter}

To request an Information Packet containing contest entry forms, rules and regulations, questions and answers about the awards, a sample of the judges' evaluation form, names of the contest judges, and a list of previous winners, please write to: Library Relations Department, The H.W. Wilson Company, 950 University Avenue, Bronx, NY 10452. 


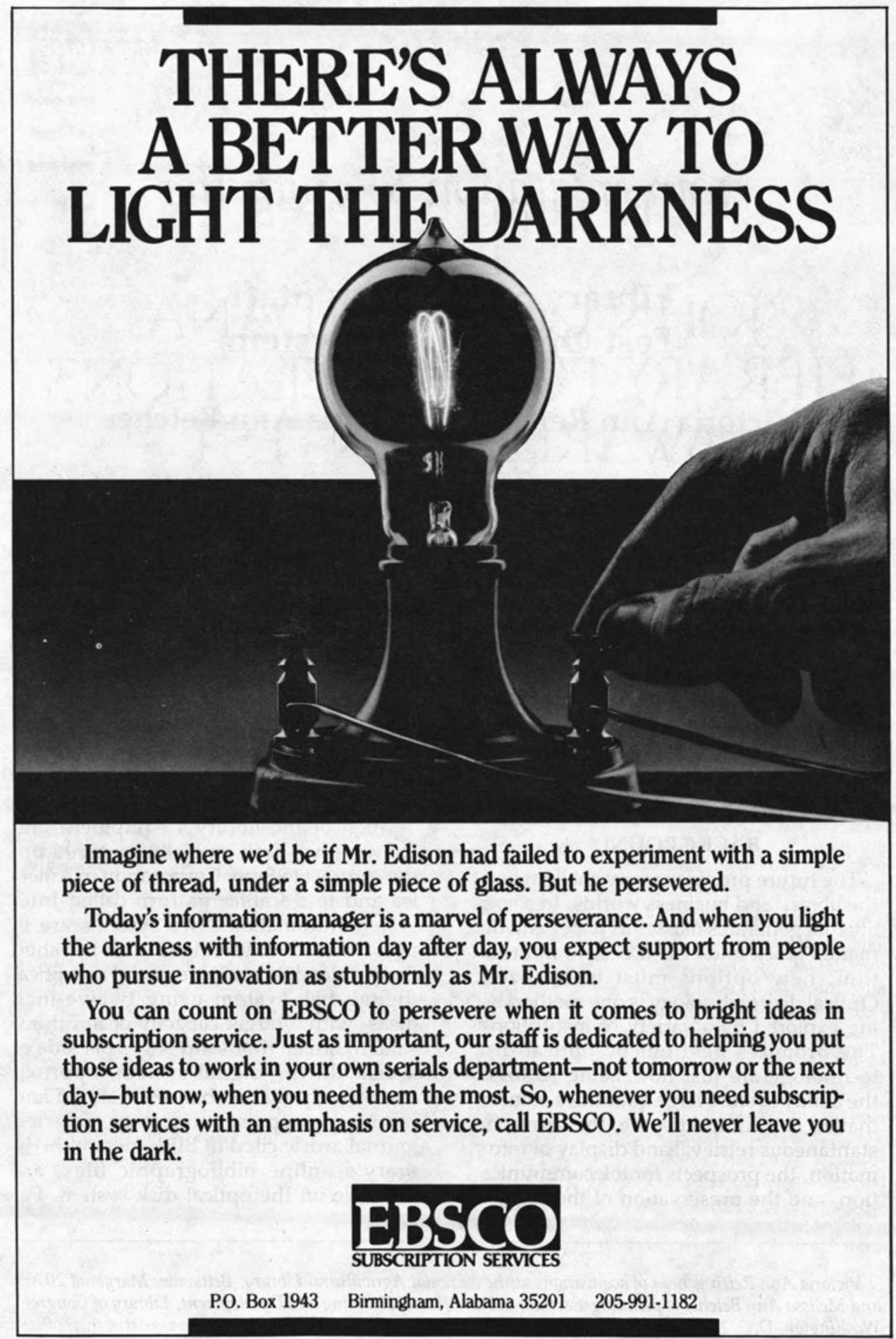

